\title{
Low-Temperature Sintering of Alumina with Liquid-Forming Additives
}

\author{
Liang A. Xue* and I-Wei Chen* \\ Department of Materials Science and Engineering, The University of Michigan, \\ Ann Arbor, Michigan 48109
}

\begin{abstract}
Simultaneous application of colloidal processing and liquidforming additives to alumina resulted in a sintered density of $>99 \%$ in $1 \mathrm{~h}$ at a temperature as low as $1070^{\circ} \mathrm{C}$ for a commercial high-purity alumina powder at a total dopant level of 2 mol\%. The additives were $0.9 \% \mathrm{CuO}+0.9 \%$ $\mathrm{TiO}_{2}+0.1 \% \mathrm{~B}_{2} \mathrm{O}_{3}+0.1 \% \mathrm{MgO}$. At higher temperatures or after prolonged sintering, the doped alumina ceramic developed a duplex microstructure containing large elongated grains and exhibited a relatively high fracture toughness of $\sim 3.8 \mathrm{MPa} \cdot \mathrm{m}^{1 / 2}$ as compared to a value of $\sim 2.6 \mathrm{MPa} \cdot \mathrm{m}^{1 / 2}$ for the undoped alumina. [Key words: sintering, alumina, additives, processing, microstructure.]
\end{abstract}

\section{Introduction}

$\mathbf{T}$ HERE are two general approaches to enhancing sintering kinetics or lowering the sintering temperature for ceramics. The first is to improve powder processing, that is, to use fine starting powders ${ }^{1}$ and to eliminate agglomerates in the green preforms, ${ }^{2-4}$ such as by colloidal routes. ${ }^{5}$ The second approach is to use sintering aids or additives. Additives in solid solutions can enhance diffusion and hence sintering by increasing defect populations, ${ }^{6,7}$ while additives forming a liquid phase can facilitate particle rearrangement and solution/reprecipitation. ${ }^{8}$

For alumina, as an extreme example of the first approach, Yeh and Sacks ${ }^{9}$ used colloidal processing with a specially classified ultrafine powder to achieve a sintered density of $99.2 \%$ at $1150^{\circ} \mathrm{C}$ in $2 \mathrm{~h}$. On the other hand, Cutler et al. ${ }^{10}$ used $4 \mathrm{wt} \%$ additives (about an equal amount of either $\mathrm{TiO}_{2}+\mathrm{Cu}_{2} \mathrm{O}$ or $\mathrm{TiO}_{2}+\mathrm{MnO}_{2}$ ) to achieve $96 \%$ of theoretical density at $1300^{\circ} \mathrm{C}$ in $1 \mathrm{~h}$. This compares with a more typical sintering temperature of $1500^{\circ}$ to $1700^{\circ} \mathrm{C}$ for high-purity alumina in normal laboratory practice. Further improvement has been made recently by Cannon, ${ }^{11}$ who achieved a $99 \%$ density at $1200^{\circ} \mathrm{C}$ in $1 \mathrm{~h}$ by doping alumina with one of Cutler's additive compositions, i.e., 2 mol\% $\mathrm{CuO}+2 \mathrm{~mol} \% \mathrm{TiO}_{2}$.

The simultaneous application of the above two approaches has not been exploited for alumina. In this paper, we show that they can result in a sintering temperature below $1100^{\circ} \mathrm{C}$, and some beneficial effects on the mechanical properties.

\section{Experimental Procedure}

The starting material was a high-purity ( $>99.99 \%)$ alumina powder* with an average particle size of $\sim 0.2 \mu \mathrm{m}$. The additive composition expressed in mole percent was $0.9 \%$ $\mathrm{CuO}+0.9 \% \mathrm{TiO}_{2}+0.1 \% \mathrm{~B}_{2} \mathrm{O}_{3}+0.1 \% \mathrm{MgO}$. This compo-

C. A. Handwerker-cont ributing editor

Manuscript No. 197038. Received December 26, 1990; approved April 30, 1991.

*Member, American Ceramic Society.

*TM-D, Taimei Chemicals, Tokyo, Japan. sition is similar to that used by Cannon, but the total additive amount is smaller. Of the two minor additives, $\mathrm{B}_{2} \mathrm{O}_{3}$ seemed to enhance sintering, whereas $\mathrm{MgO}$ seemed to improve microstructure uniformity. ${ }^{12}$

The alumina powder was ultrasonically dispersed in distilled water with a surfactant. ${ }^{\dagger}$ Additives were introduced by adding aqueous solutions of $\mathrm{Cu}\left(\mathrm{NO}_{3}\right)_{2}, \mathrm{Mg}\left(\mathrm{NO}_{3}\right)_{2}$, and $\mathrm{H}_{3} \mathrm{BO}_{3}$ and ethanol solution of $\mathrm{Ti}\left\{\mathrm{O}\left(\mathrm{CH}_{2}\right)_{3} \mathrm{CH}_{3}\right\}_{4}$ to the dispersed suspension of alumina powder. The $\mathrm{pH}$ of the mixture was then adjusted to flocculate the suspension. The slurry was dried and calcined at $700^{\circ} \mathrm{C}$ for $1 \mathrm{~h}$. A portion of the powder thus obtained was dried and then die-pressed under a compaction pressure of $150 \mathrm{MPa}$ into pellets (process $\mathrm{A}$ ). The rest was dispersed again, by attrition-milling and ultrasonic agitation, then pressure-cast into cakes as described elsewhere $^{13}$ (process B). Shrinkage during nonisothermal sintering experiments was recorded in a dilatometer ${ }^{\ddagger}$ at a heating rate of $5^{\circ} \mathrm{C} / \mathrm{min}$ up to $1450^{\circ} \mathrm{C}$. Isothermal sintering experiments were conducted in the temperature range of $1070^{\circ}$ to $1200^{\circ} \mathrm{C}$ for times up to $5 \mathrm{~h}$.

To measure the hardness and the fracture toughness of the sintered samples, a Vickers indentation technique was employed, ${ }^{14}$ using a load range of 4 to $15 \mathrm{~kg}$. Flextural strength measurements were performed in four-point bending for specimens of dimensions $2.0 \mathrm{~mm} \times 3.0 \mathrm{~mm} \times 20.0 \mathrm{~mm}$ with a 4-mm inner span and a $17-\mathrm{mm}$ outer span.

\section{Results and Discussion}

Figure 1 shows sintering curves of undoped and doped alumina, compacted in two processes. For the undoped material,

\footnotetext{
${ }^{\dagger}$ Darvan 821A, R.T. Vanderbilt Co., Norwalk, CT.

${ }^{\ddagger}$ Theta Dilatronic, Theta Industries, Inc., Port Washington, NY.
}

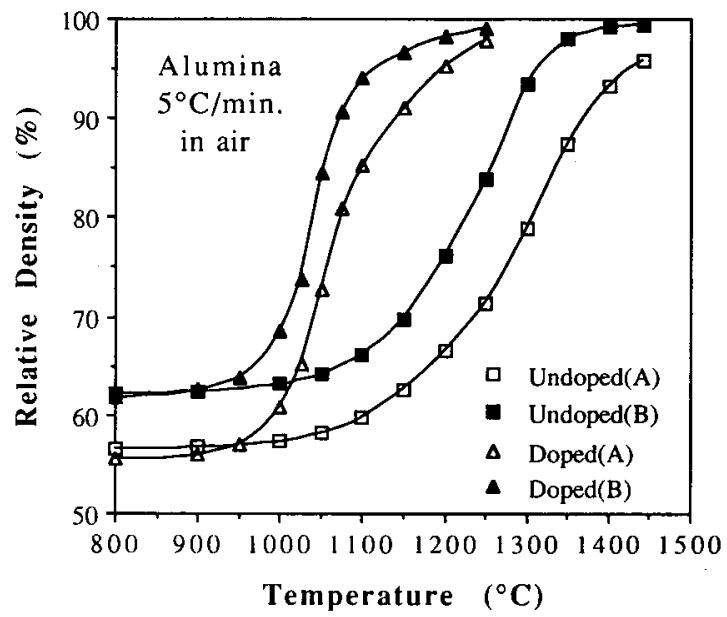

Fig. 1. Sintering curves for doped and undoped alumina. Processes A and B are described more fully in the text.) 


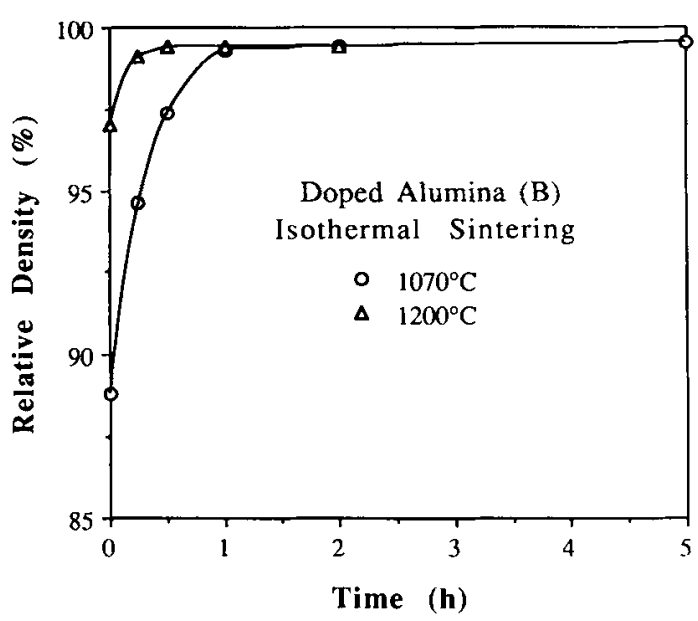

Fig. 2. Sintered density of doped alumina (B) as a function of time for isothermal sintering at $1070^{\circ}$ and $1200^{\circ} \mathrm{C}$.

the colloidally processed specimen (B) gives a significantly faster sintering rate than that of the conventionally processed one (A). For instance, the former achieves a density of $98 \%$ of the theoretical at $1350^{\circ} \mathrm{C}$, while the latter reaches only $95.9 \%$ even at $1450^{\circ} \mathrm{C}$. For doped alumina, sintering starts at a much lower temperature and seems to be much less sensitive to the variation of compacting processes. Nevertheless, the colloidal process (B) still has an advantage over the other process. For example, at $1200^{\circ} \mathrm{C}$ the colloidal processed sample reaches a density of $98.2 \%$, a value the conventionally processed sample would obtain only after an $80^{\circ} \mathrm{C}$ temperature increase, i.e., at $1280^{\circ} \mathrm{C}$.

The above results can be qualitatively understood as follows. First, process A yields a less efficient packing of powders than process $B$, as evidenced by its lower green density (59\% in $\mathrm{A}$ as compared to $65 \%$ in $\mathrm{B}) .^{\S}$ Mercury porosimetry has further shown the presence of a larger average pore size and a broader pore size distribution in process $\mathrm{A}$. These fea-

\footnotetext{
${ }^{\S}$ The relative density curves in Fig. 1 are calculated from the end densities and the dilatometry traces, assuming isotropic linear shrinkage for the specimens. However, the measured shrinkage in the thickness direction is larger than those in the radial direction by about $1 \%$. Therefore, the calculated starting densities in Fig. 1 are lower by about $3 \%$ than the actual green densities. This deviation, although noticeable in the low density range, does not af fect the comparison of the relative density data.
}

tures are known to retard effective sintering. ${ }^{2,15}$ Second, a low-temperature eutectic is likely to exist between $\mathrm{Al}_{2} \mathrm{O}_{3}$, $\mathrm{CuO}, \mathrm{Cu}_{2} \mathrm{O}, \mathrm{TiO}_{2}, \mathrm{MgO}$, and $\mathrm{B}_{2} \mathrm{O}_{3}$. The eutectic temperature is probably lower than $1000^{\circ} \mathrm{C}$, considering the known eutectic of $1096^{\circ} \mathrm{C}$ between $\mathrm{Al}_{2} \mathrm{O}_{3}-\mathrm{CuO}-\mathrm{Cu}_{2} \mathrm{O} .^{16}$ To estimate the eutectic temperature range, a DTA run has been conducted at a heating rate of $5^{\circ} \mathrm{C} / \mathrm{min}$ for powder obtained by crushing a piece of the doped alumina (B) cake. An endothermic peak has indeed been found, which starts gradually at $\sim 1040^{\circ} \mathrm{C}$ and begins to accelerate around $1130^{\circ} \mathrm{C}$ before peaking at $1167^{\circ} \mathrm{C}$. Since the DTA experiment employs loosely packed powder as contrast to the densely packed pellets used in sintering, the endothermic peak would somewhat shift to a lower temperature for the sintering samples. Thus, liquidphase sintering is probably operative in the doped alumina. Moreover, the presence of a liquid phase is known to render sintering more forgiving to processing flaws introduced by unsatisfactory powder packing processes. Lastly, the codoping of $\mathrm{Ti}$ and $\mathrm{Cu}$ is also known to increase the solubility of each, due to mutual charge compensation. This may, in turn, allow an additional contribution to enhance kinetics. ${ }^{11,17}$

For the doped alumina (B) the densities achieved after isothermal sintering at two different temperatures are plotted as a function of sintering time in Fig. 2. At $1070^{\circ} \mathrm{C}, 99.3 \%$ relative density was obtained in $1 \mathrm{~h}$, which appeared to be the optimal sintering time since longer time did not increase the density much. At $1200^{\circ} \mathrm{C}$, the sintering kinetics were so fast that a $99.1 \%$ density was reached in $15 \mathrm{~min}$. However, the higher sintering temperature did not result in higher densities for sintering time longer than $1 \mathrm{~h}$.

The microstructure of a doped alumina (process B) sintered at $1070^{\circ} \mathrm{C}$ for $1 \mathrm{~h}$ is shown in Fig. 3(A), which features a very fine grain size (average grain size $0.33 \mu \mathrm{m}$ ) almost free of porosity $(\rho=99.3 \%)$. If the sintering temperature is raised or prolonged isothermal heating is used, however, a new duplex microstructure is developed. This is shown in Fig. 3(B), for a sample sintered at $1110^{\circ} \mathrm{C}$ for $1 \mathrm{~h}$, which has a substantial amount of large, elongated abnormal grains, of a size around $20 \mu \mathrm{m}$ with an aspect ratio 3 to 10 , embedded in a finegrained $(0.38 \mu \mathrm{m})$ matrix. These elongated grains become entirely dominant at an even higher sintering temperature, as can be seen in Fig. 3(C), for a sample sintered at $1200^{\circ} \mathrm{C}$. Abnormal grain growth at such a low temperature is rare in high-purity alumina, and strongly faceted abnormal grains are frequently observed in liquid-phase-sintered alumina; ${ }^{18,19}$ therefore, the observed microstructure here is no doubt due to the presence of a liquid phase. Moreover, liquid phases

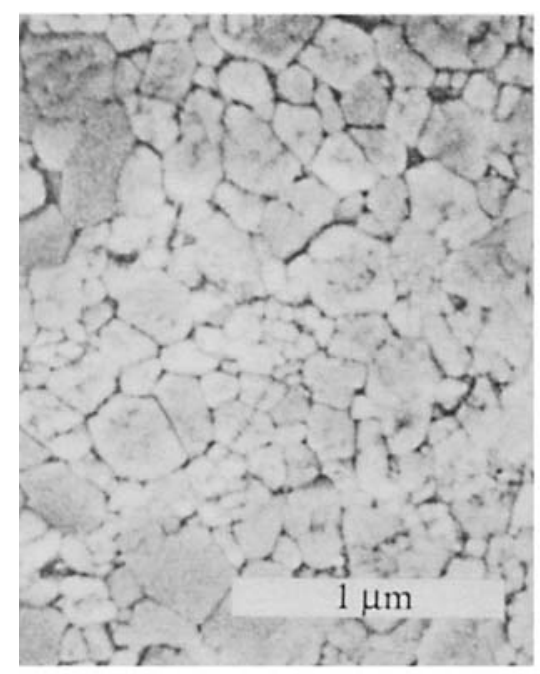

(A)

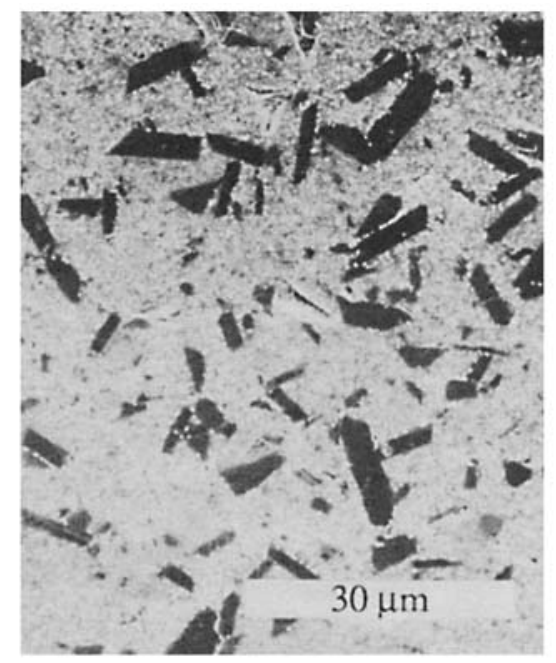

(B)

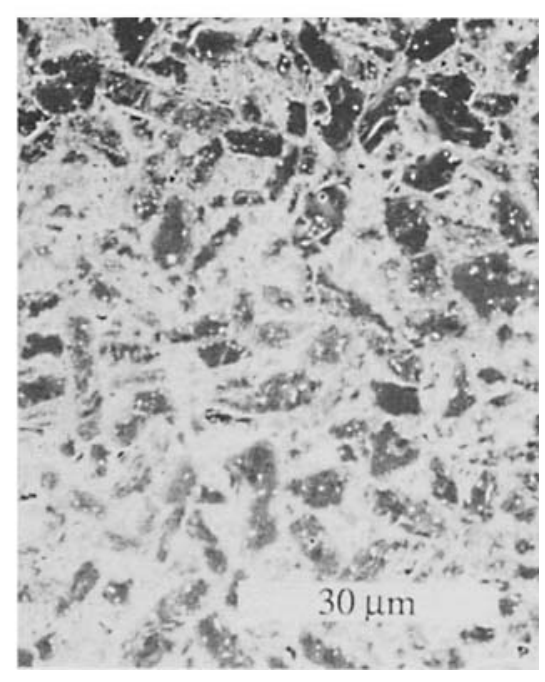

(C)

Fig. 3. SEM micrographs of the doped alumina sintered at various temperatures for $1 \mathrm{~h}:$ (A) $1070^{\circ}$, (B) $1110^{\circ}$, and (C) $1200^{\circ} \mathrm{C}$. 
containing compensating dopants (e.g., $\mathrm{TiO}_{2}+\mathrm{CaO}$, $\mathrm{SiO}_{2}+\mathrm{SrO}$, and $\mathrm{SiO}_{2}+\mathrm{Na}_{2} \mathrm{O}$ ) are found particularly effective in producing elongated, platelike abnormal grains. ${ }^{19}$ The two major additives in the present study, $\mathrm{TiO}_{2}$ and $\mathrm{CuO}$, are a compensating pair to alumina.

Some beneficial effects of such a duplex microstructure on mechanical properties have been observed in this study. Flexure strength for specimens shown in Fig. 3(B) is $396 \pm 41$ $\mathrm{MPa}$, about the same as for an undoped alumina with an average grain size $0.5 \mu \mathrm{m}$. More encouragingly, the fracture toughness is between 3.60 and $4.17 \mathrm{MPa} \cdot \mathrm{m}^{1 / 2}$, compared favorably to values of 2.41 to $2.76 \mathrm{MPa} \cdot \mathrm{m}^{1 / 2}$ for the undoped alumina. A similar observation has been reported for an alumina/rutile system, ${ }^{20}$ where the development of abnormal elongated grains promoted by $\mathrm{Na}_{2} \mathrm{O}$, a liquid phase former, resulted in a significantly higher fracture toughness.

\section{Summary}

Both colloidal processing and the use of additives can reduce the sintering temperature of alumina, the latter being more effective. When these two approaches are combined, a commercial high-purity alumina powder can be sintered to a relative density of $99.3 \%$ at $1070^{\circ} \mathrm{C}$ in $1 \mathrm{~h}$, at an additive concentration of no more than 2 mol\%. A duplex microstructure can also be promoted by doping which results in an improved fracture toughness.

\section{References}

${ }^{1} \mathrm{C}$. Herring, "Effect of Change of Scale on Sintering Phenomena," J. Appl. Phys., 21 [4] 301-303 (1950).

${ }^{2} W$. H. Rhodes, "Agglomerate and Particle Size Effects on Sintering YttriaStabilized Zirconia," J. Am. Ceram. Soc., 64 [1] 19-22 (1981).

${ }^{3}$ F. F. Lange, "Sinterability of Agglomerated Powders," J. Am. Ceram. Soc., 67 [2] 83-89 (1984).

${ }^{4}$ R.T. Tremper and R. S. Gordon, "Agglomeration Effects on the Sintering of Alumina Powders Prepared by Autoclaving Aluminum Metal"; pp. 15376 in Ceramic Processing Before Firing. Edited by G. Onoda and L. L. Hench. Wiley, New York, 1978.
${ }^{5}$ F. F. Lange, "Powder Processing Science and Technology for Increased Reliability,"J. Am. Ceram. Soc., 71 [1] 3-15 (1988).

'D.W. Readey, "Mass Transport and Sintering of Impure Ionic Solids," Am. Ceram. Soc., 49 [7] 366-69 (1966).

${ }^{7}$ R. D. Bagley, I. B. Cutler, and D. L. Johnson, "Effect of $\mathrm{TiO}_{2}$ on Initial Sintering of $\mathrm{Al}_{2} \mathrm{O}_{3}$, J. Am. Ceram. Soc., 53 [3] 136-41 (1970).

${ }^{8}$ W. D. Kingery, "Densification during Sintering in the Presence of a Liquid Phase. I. Theory," J. Appl. Phys., 30 [3] 301-306 (1959).

${ }^{9}$ T.-S. Yeh and M.D. Sacks, "Low-Temperature Sintering of Alumina Oxide," J. Am. Ceram. Soc., 71 [10] 841-44 (1988).

${ }^{10}$ I. B. Cutler, C. Bradshaw, C. J. Christensen, and E. P. Hyatt, "Sintering of Alumina at Temperatures of $1400^{\circ} \mathrm{C}$ and Below," J. Am. Ceram. Soc., 40 [4] 134-39 (1957).

"W. R. Cannon "High Creep Ductility in Alumina Containing Compensating Additives"; pp. 741-49 in Advances in Ceramics, Vol. 10, Structure and Properties of $\mathrm{MgO}$ and $\mathrm{Al}_{2} \mathrm{O}_{3}$ Ceramics. Edited by W. D. Kingery. American Ceramic Society, Columbus, OH, 1984.

${ }^{12}$ M. P. Harmer, "Use of Solid-Solution Additives in Ceramic Processing"; pp. 679-96 in Advances in Ceramics, Vol. 10, Structure and Properties of $\mathrm{MgO}$ and $\mathrm{Al}_{2} \mathrm{O}_{3}$ Ceramics. Edited by W.D. Kingery. American Ceramic Society, Columbus, $\mathrm{OH}, 1984$.

${ }^{13}$ L. A. Xue and I-W. Chen, "Deformation and Grain Growth of LowTemperature Sintered High Purity Alumina," J. Am. Ceram. Soc., 73 [11] $3518-21(1990)$.

${ }^{14}$ G. R. Anstis, P. Chantikul, B. R. Lawn and D. B. Marshall "A Critical Evaluation of Indentation Techniques for Measuring Fracture Toughness: I, Direct Crack Measurements," J. Am. Ceram. Soc., 64 [9] 533-38 (1981).

${ }^{15}$ M. A. Occhionero and J.W. Halloran, "The Influence of Green Density Upon Sintering"; pp. 89-102 in Sintering and Heterogeneous Catalysis. Edited by G. C. Kuczynski, A. E. Miller, and G. A. Sargent. Plenum Press, New York, 1984.

${ }^{16} \mathrm{~A} . \mathrm{M}$. Cadalla and J. White, "Equilibrium Relationships in the System $\mathrm{CuO}-\mathrm{Cu}_{2} \mathrm{O}-\mathrm{Al}_{2} \mathrm{O}_{3}$," Trans. Br. Ceram. Sac., 63 [1] 39-62 (1964).

${ }^{17} \mathrm{Y}$. Ikuma and R. S. Gordon, "Effect of Doping Simultaneously with Iron and Titanium on the Diffusional Creep of Polycrystalline $\mathrm{Al}_{2} \mathrm{O}_{3}$, $J$. Am. Ceram. Soc., 66 [2] 139-47 (1983).

${ }^{18}$ W. A. Kaysser, M. Sprissler, C. A. Handwerker, and J. E. Blendell, "Effect of a Liquid Phase on the Morphology of Grain Growth in Alumina, J. Am. Ceram. Soc., 70 [5] 339-43 (1987).

${ }^{19} \mathrm{H}$. Song and R. L. Coble, "Origin and Growth Kinetics of Platelike Abnormal Grains in Liquid-Phase-Sintered Alumina," J. Am. Ceram. Soc., 73 [7] 2077-85 (1990).

${ }^{20}$ S. Hori, H. Kaji, M. Yoshimura, and S. Somiya, "Deflection-Toughened Corundum-Rutile Composites"; pp. 283-88 in Advanced Structural Ceramics. Edited by P. F. Becher, M.V. Swain, and S. Somiya. Materials Research Society, Pittsburgh, PA, 1987. 